\title{
Serum Vitamin D Status and Outcome in Critically III Children
}

\author{
Nazik Aşılıŏlu, Halit Çiğdem¹, Muhammed Sükrü Paksu \\ Division of Pediatric Critical Care, Ondokuz Mayis University School of Medicine, ${ }^{1}$ Department of Pediatrics, Ondokuz Mayis University School of Medicine, \\ Samsun, Turkey
}

\section{Abstract}

Background: Vitamin D is a pleiotropic hormone essential for optimal health. Critical illness in children is a major cause of significant health-care utilization and mortality around the world. The association of Vitamin D deficiency (VDD) in critically ill adults has been well-studied, in comparison, the importance of Vitamin D in pediatric critical illness has been much less studied. Aim and Objectives: This study aimed to assess Vitamin D status and its determinants in patients admitted to a pediatric intensive care unit (PICU) in North of Turkey. We also investigated the association between Vitamin D status and clinical outcomes. Materials and Methods: All patients aged 1 month to 18 years admitted to the PICU of a tertiary care hospital who had levels of 25-hydroxy Vitamin D available within 24 h of admission were included in this retrospective study. VDD was defined as $<20 \mathrm{ng} / \mathrm{mL}$ levels. Results: VDD was observed in 120 (58.5\%) children. In multivariable linear regression model, only identified patient age and winter season as statistically associated with VDD. Vitamin D deficient patients were older and heavier and were more likely to receive catecholamine. There was no association between Vitamin D deficiency and other illness severity factors including mortality. Conclusions: Hypovitaminosis D occurrence was high in critically ill children and was associated with higher vasopressor requirement but not with other markers of illness severity including mortality.

Keywords: 25-hydroxyvitamin D, illness severity, mortality, pediatric intensive care

\section{INTRODUCTION}

Vitamin D is a pleiotropic hormone essential for optimal health. Vitamin D status has been associated with diseases involving dysregulation of the immune, cardiovascular, and respiratory systems. Levels of 25-hydroxy Vitamin D (25[OH]D) are most often used to assess the adequacy of Vitamin D stores. It is less clear what impact deficiency has on the critically ill. Critical illness in children is a major cause of significant health-care utilization and mortality worldwide. The concern is especially understandable in developing countries with limited resources. The association of Vitamin D deficiency (VDD) in critically ill adults has been well-studied, with a recent meta-analysis demonstrating a significant increase in infection rate, sepsis, and mortality in deficient patients. ${ }^{[1]}$ In comparison, the importance of Vitamin D in pediatric critical illness has been much less studied. Recent research of critically ill children has demonstrated that VDD is common and a few studies have also identified that VDD is associated with more severe illness and a longer stay in the pediatric intensive care unit (PICU). ${ }^{[2-7]}$ No consensus has as yet been reached regarding the optimal definition of VDD nor the threshold levels to define health

\begin{tabular}{|l|l|}
\hline \multicolumn{3}{c|}{ Access this article online } \\
\hline Quick Response Code: & Website: \\
& www.ijccm.org \\
\cline { 2 - 2 } & \\
\end{tabular}

benefits. Due to the lack of interventional studies to show that administration of Vitamin D improves clinical outcomes, opinion is still divided as to whether it is association or causality. The evidence of Vitamin D status in critically ill children is lacking from developing countries, especially Turkey. Therefore, the objective of this study was to assess the prevalence of VDD in critically ill children admitted to the PICU, to assess the determinants of Vitamin D status and to assess the association between Vitamin D status and illness severity.

\section{Materials and Methods}

This was a retrospective study in which all children aged $\leq 18$ years ( 1 month to $\leq 18$ years) admitted to the 12 bed medical-surgical PICUs from June 2014 to November 2015 were screened. There were 570 total admissions to the PICU

Address for correspondence: Dr. Nazik Aşlıoğlu, Division of Pediatric Critical Care, Ondokuz Mayis University School of Medicine, Samsun, Turkey. E-mail: nazika@omu.edu.tr

This is an open access article distributed under the terms of the Creative Commons Attribution-NonCommercial-ShareAlike 3.0 License, which allows others to remix, tweak, and build upon the work non-commercially, as long as the author is credited and the new creations are licensed under the identical terms.

For reprints contact: reprints@medknow.com

How to cite this article: Aşılığlu N, Çiğdem H, Paksu MS. Serum vitamin D status and outcome in critically Ill children. Indian J Crit Care Med 2017;21:660-4. 
during the study. All patients admitted to the PICU who had levels of 25(OH)D available within $24 \mathrm{~h}$ of admission were included in the study. Only the first PICU admission of each patient was included in the study. 25(OH)D levels were collected randomly during the first $24 \mathrm{~h}$ of admission to the PICU.

The patient demographic and clinical data were recorded on PICU admission, including age, gender, body mass index (BMI) $\left(\mathrm{kg} / \mathrm{m}^{2}\right)$, underlying illness, reason for admission, season and history of Vitamin D supplementation. Laboratory variables obtained during the first $24 \mathrm{~h}$ of hospital admission which included serum levels of total calcium, ionized calcium, phosphate, magnesium and 25(OH)D were analyzed.

Blood samples were drawn during routine phlebotomy on admission to the PICU. All tests were performed by routine methods employed in the biochemistry laboratory of our university hospital. 25(OH)D was measured once a week. Samples were protected from exposure to sunlight, centrifuged and stored under refrigeration until processing. The level of $25(\mathrm{OH}) \mathrm{D}$ was measured using chromatography together with the tandem mass spectrometry method (Zivak Technologies, Kocaeli, Turkey) and was reported in $\mathrm{ng} / \mathrm{mL}$. VDD was defined as a level of $25(\mathrm{OH}) \mathrm{D}<20 \mathrm{ng} / \mathrm{ml} .^{[5-7]}$ All the paediatric cases included in the study were divided into two groups as Vitamin D sufficient $(25[\mathrm{OH}] \mathrm{D} \geq 20 \mathrm{ng} / \mathrm{ml})$ or Vitamin D deficient $(25[\mathrm{OH}] \mathrm{D}<20 \mathrm{ng} / \mathrm{ml})$.

The primary outcome measure was the occurrence of VDD in critically ill children. Secondary outcomes were to assess the determinants of Vitamin D status and to compare Vitamin D deficient and sufficient cases in respect of severity of illness. The variables used as measures of illness severity included the pediatric risk of mortality (PRISM III) score, catecholamine requirements, mechanical ventilation, PICU length of stay (LOS), and mortality. Sepsis was defined as a systemic inflammatory response syndrome in the presence of suspected or confirmed infection by any pathogen in the blood or cerebrospinal fluid..$^{[8]}$ This study was approved by the Local Ethics Committee of Ondokuz Mayis University (Samsun, Turkey).

The statistical analyses of the data obtained in the study were made using SPSS 21 software (IBM Corp. in Armonk, NY, USA). The evaluation was made under the 3 headings of descriptive, single variable and multivariable analysis methods. Numerical data were stated as median (interquartile range $[\mathrm{IQR}])$ and mean \pm standard deviation (SD). Categorical data were stated as number $(n)$ and percentage (\%).

Conformity of the data to normal distribution was evaluated. In the comparisons between independent groups, for numerical variables not showing normal distribution, the Mann Whitney U-test was used for the comparisons between two groups and for more than two groups, Kruskal-Wallis nonparametric variance analysis was applied. In the comparison of categorical data between independent groups, Chi-square statistics were applied. In the multi-variable analyses, the Cox regression model was applied for censored time-to-event data, a logistic regression model for dichotomsed data when mortality was examined, and a multi-variable linear regression model in the quantitative evaluation of Vitamin D level. In all the statistical evaluations of the study, a 2-way hypothesis structure and 5\% Type-1 error level were used.

\section{RESULTS}

The baseline characteristics of the cohort are shown in Table 1 . The study included a total of 205 critically ill children with a median age of 47 months (IQR 11-125 months). Seventy-eight patients (38\%) were younger than 2 years. The main reasons for PICU admission were neurologic diseases $(43.21 \%)$, respiratory tract infections $(41.20 \%)$ and sepsis $(30,14.6 \%)$. According to the family history, 55 patients were taking Vitamin D supplementation before admission, and the majority $(n=43,78.2 \%)$ were younger than 2 years. The mean $25(\mathrm{OH}) \mathrm{D}$ level of the whole groups

\begin{tabular}{|c|c|}
\hline Variable & $(n=205)$ \\
\hline Age (month), median (IQR) & $47(11-125)$ \\
\hline Male, $n(\%)$ & $22(59.5)$ \\
\hline Weight (kg), median (IQR) & $15(8-30)$ \\
\hline Height $(\mathrm{cm})$, median (IQR) & $100(70-134)$ \\
\hline BMI $\left(\mathrm{kg} / \mathrm{m}^{2}\right)$, median (IQR) & $16.6(13.8-19.2)$ \\
\hline \multicolumn{2}{|l|}{ Admission season, $n(\%)$} \\
\hline Summer & $92(44.9)$ \\
\hline Fall & $28(13.7)$ \\
\hline Winter & $39(19)$ \\
\hline Spring & $46(22.4)$ \\
\hline \multicolumn{2}{|l|}{ Reason for PICU admission, $n(\%)$} \\
\hline Neurological diseases & $43(21)$ \\
\hline Acute respiratory infections & $41(20)$ \\
\hline Sepsis & $30(14.6)$ \\
\hline Trauma & $26(12.7)$ \\
\hline Intoxications & $23(11.2)$ \\
\hline Postoperative diseases & $21(10.2)$ \\
\hline Others & $21(10.2)$ \\
\hline Underlying illness, $n(\%)$ & $112(54.6)$ \\
\hline PRISM III score, median (IQR) & $5(0-29)$ \\
\hline Mechanical ventilation, $n(\%)$ & $110(53.7)$ \\
\hline PICU stay (days) median (IQR) & $4.5(2-10)$ \\
\hline Catecholamine requirements, $n(\%)$ & $65(31.7)$ \\
\hline Mortality $n(\%)$ & $25(12.1)$ \\
\hline \multicolumn{2}{|l|}{ Laboratory investigations, mean $\pm \mathrm{SD}$} \\
\hline Total calcium $(\mathrm{mg} / \mathrm{dL})$ & $9.2 \pm 1$ \\
\hline Phosphate (mg/dL) & $4.2 \pm 1.8$ \\
\hline Ionized calcium $(\mathrm{mmol} / \mathrm{L})$ & $3.3 \pm 0.8$ \\
\hline Magnesium (mmol/L) & $0.9 \pm 0.2$ \\
\hline $25(\mathrm{OH}) \mathrm{D}(\mathrm{ng} / \mathrm{mL})$ & $19.9 \pm 11.8$ \\
\hline
\end{tabular}


was $19.9 \pm 11.8 \mathrm{ng} / \mathrm{ml}$. VDD $(25[\mathrm{OH}] \mathrm{D}$ levels $<20 \mathrm{ng} / \mathrm{ml})$ was determined in $120(58.5 \%)$ children with a higher prevalence (76.7\%) in children older than 2 years. A history of Vitamin D supplementation was associated with higher $25(\mathrm{OH})$ vit D levels. The mean 25(OH)D levels were higher in children with a history of Vitamin D supplementation compared to children with no Vitamin D supplementation $(29.5 \pm 13.1 \mathrm{ng} / \mathrm{mL}$ vs. $16.5 \pm 9.2 \mathrm{ng} / \mathrm{mL}, P<0.001)$. The mean $25(\mathrm{OH}) \mathrm{vitD}$ levels were lower $(16.7 \pm 11.1 \mathrm{ng} / \mathrm{ml})$ in the children who had sepsis at admission compared to other critically ill patient groups $(20.6 \pm 12.2)$, but the difference was not statistically significant $(P=0.08)$. Twenty-five $(12.1 \%)$ patients died during PICU hospitalization. Although the mean 25(OH) $\mathrm{D}$ levels were lower in the children who died compared to those who survived [18.5 $\pm 9.4 \mathrm{ng} / \mathrm{ml}$ vs. $20.1 \pm 12.2 \mathrm{ng} / \mathrm{ml}]$, the difference was not statistically significant $(P=0.778)$.

The characteristics of Vitamin D deficient and sufficient children were compared [Table 2]. There were no gender differences between the groups, but the Vitamin D deficient patients were older and heavier. Vitamin D deficient children had a significantly higher median age compared to the Vitamin D sufficient children (73 months [IQR: 29.5-158] vs. 14 months [IQR: 7-79] $)(P<0.001)$ Linear regression analysis demonstrated that for every 1 month increase in age there was a $0.353 \mathrm{ng} / \mathrm{mL}$ decrease in Vitamin D level $(95 \%$ confidence interval [CI]: $-0.082--0.038)$. Vitamin D deficient children had a significantly higher median weight compared to Vitamin D sufficient children $(20 \mathrm{~kg}[11-40]$ vs. $10 \mathrm{~kg}[6.5-20])(P<0.001)$ Vitamin Ddeficient patients had higher BMI values $\left(17[14.2-19.7] \mathrm{kg} / \mathrm{m}^{2}\right.$ vs. 15.9 [13.5-18.6] kg/m²), but there was no statistically significant difference $(P=0.0149)$. Of the total patients hospitalized during the autumn and winter months, $76 \%$ were considered to be Vitamin D deficient, whereas in the sunnier seasons (spring and summer), almost $50 \%$ of patients were considered as Vitamin D deficient $(P=0.002)$. The underlying disease incidence was slightly higher in the Vitamin D sufficient patients (57.6\% vs. $52.5 \%$; $P=0.466)$. Although catecholamine requirements were significantly higher in Vitamin D deficient patients (37.5\% vs. $23.5 \% P=0.034$ ), no statistically significant difference was determined between the groups in respect of main admission reasons, underlying illnesses, PICU LOS, PRISM III score, need for mechanical ventilation and mortality. There was no association between the admission levels of ionized calcium, phosphate, magnesium and Vitamin D status. However, the lowest measured calcium within the first $24 \mathrm{~h}$ was significantly lower in children with VDD $(9 \pm 1 \mathrm{mg} / \mathrm{dL}$ vs. $9.5 \pm 0.9 \mathrm{mg} / \mathrm{dL})(P<0.001)$.

In the multivariable linear regression model, only patient age (relative risk [RR]: -0.353 ; 95\% CI: $-0.084-0.036$; $P<0.001$ ) and winter season admission (RR: -0.247 ; 95\% CI: $-11.492--3.366 ; P<0.001)$ were identified as

Table 2: Demographic, clinical, and laboratory data in patients with or without Vitamin D deficiency

\begin{tabular}{|c|c|c|c|}
\hline & \multicolumn{2}{|c|}{$25(\mathrm{OH}) \mathrm{D}$} & \multirow[t]{2}{*}{$P$} \\
\hline & $\leq 20 \mathrm{ng} / \mathrm{mL}(n=120)$ & $>20 \mathrm{ng} / \mathrm{mL}(n=85)$ & \\
\hline Male, $n(\%)$ & $70(58.3)$ & $52(61.2)$ & 0.683 \\
\hline Age (month), median (IQR) & $73(29.5-158)$ & $14(7-79)$ & $<0.001$ \\
\hline Weight (kg), median (IQR) & $20(11-40)$ & $10(6.5-20)$ & $<0.001$ \\
\hline BMI $\left(\mathrm{kg} / \mathrm{m}^{2}\right)$, median (IQR) & $17.5(14.2-19.7)$ & $15.9(13.5-18.6)$ & 0.149 \\
\hline \multicolumn{4}{|l|}{ Admission season, $n(\%)$} \\
\hline Spring & $20(16.7)$ & $26(30.6)$ & 0.002 \\
\hline Summer & $49(40.8)$ & $43(50.6)$ & \\
\hline Fall & $20(16.7)$ & $8(9.4)$ & \\
\hline Winter & $31(25.8)$ & $8(9.4)$ & \\
\hline \multicolumn{4}{|l|}{ Main admission diagnosis, $n(\%)$} \\
\hline Neurological diseases & $26(21.7)$ & $17(20)$ & 0.773 \\
\hline Respiratory track infections & $19(15,8)$ & $22(25.9)$ & 0.076 \\
\hline Sepsis & $20(16.7)$ & $10(11.8)$ & 0.328 \\
\hline Underlying diseases, $n(\%)$ & $63(52.5)$ & $49(57.6)$ & 0.466 \\
\hline Mechanical ventilation $n(\%)$ & $62(51.6)$ & $48(56.5)$ & 0.497 \\
\hline Catecholamine requirements, $n(\%)$ & $45(37.5)$ & $20(23.5)$ & 0.034 \\
\hline PRISM-III score median (IQR) & $5(2-9)$ & $4(0-8)$ & 0.211 \\
\hline PICU stay (days), median (IQR) & $4(2-11)$ & $5(2-10)$ & 0.799 \\
\hline Mortality, $n(\%)$ & $16(13.3)$ & $9(10.5)$ & 0.955 \\
\hline Total calcium (mg/dL) mean $\pm \mathrm{SD}$ & $9 \pm 1$ & $9.5 \pm 0.9$ & $<0.001$ \\
\hline Phosphate $(\mathrm{mg} / \mathrm{dL})$ mean $\pm \mathrm{SD}$ & $4.1 \pm 2.1$ & $4.3 \pm 1.4$ & 0.095 \\
\hline Magnesium $(\mathrm{mmol} / \mathrm{L})$ mean $\pm \mathrm{SD}$ & $0.8 \pm 0.2$ & $0.9 \pm 0.2$ & 0.375 \\
\hline Ionized calcium $(\mathrm{mg} / \mathrm{dL})$ mean $\pm \mathrm{SD}$ & $3.3 \pm 0.8$ & $3.4 \pm 0.9$ & 0.173 \\
\hline
\end{tabular}

25(OH)D: 25-hydroxyvitamin D; IQR: Interquartile range; BMI: Body mass index; PICU: Pediatric intensive care unit; PRISM: Pediatric risk of mortality score; SD: Standard deviation 
statistically associated with VDD. The established risk factors of BMI, gender, and underlying illnesses were not independently associated with VDD. With logistic regression analysis, the factors that were significantly associated with mortality included catecholamine requirements (OR: 41.952; 95\% CI: 4.944-355.998; $P=0.001$ ) and PRISM-III score (OR: 1.162 ; 95\% CI: 1.057-1.278; $P=0.002$ ). The other factors of the presence of underlying illness, level of Vitamin D, need for mechanical ventilation, and presence of sepsis at admission were not determined to be associated with mortality [Table 3].

\section{Discussion}

The data from this study strongly suggest that the majority $(58.5 \%)$ of critically ill Turkish children are deficient in Vitamin D (25[OH]vitD levels $<20 \mathrm{ng} / \mathrm{ml})$ at admission. The prevelance of VDD (76.7\%) was higher in children older than 2 years. These levels are considerably higher than the rate of $40 \%$ reported in a previous study of 440 Turkish children and adolescents aged between 0 and 16 years who presented at the outpatient clinic ${ }^{[9]}$ The available evidence suggests occurrence ranging from approximately $30 \%$ to $84 \%$ in critically ill children. ${ }^{[2-7]}$ The wide differences in the occurrence of VDD in different studies may be due to differences in the populations studied, sunlight exposure, weather, dietary intake, Vitamin D supplementation, genotype variation in the proteins involved in Vitamin D transportation, functioning and metabolism, different methods of measuring $25(\mathrm{OH}) \mathrm{D}$, and different cut-off values. ${ }^{[10]}$

A previously described inverse correlation between $25(\mathrm{OH}) \mathrm{vitD}$ levels and age was confirmed by the present study. The data of the current study demonstrate that the prevalence of VDD in patients hospitalized during the fall and winter was significantly higher than in sunnier months. Furthermore, the multivariable linear regression model only identified patient age and winter season admission as statistically associated with VDD. Similarly, in healthy children, factors consistently associated with 25(OH)vitD levels have been reported to be age, the season of the year, and dietary calcium intake. ${ }^{[1]}$ Unfortunately, there were no available data regarding calcium intake of the children in the current study.

Vitamin D plays a physiological role in regulating immunity, and in thermodulation of T- and B-cell activity, cytokine

\begin{tabular}{|c|c|c|c|}
\hline & OR & $95 \% \mathrm{Cl}$ & $P$ \\
\hline Catecholamine requirements & 41.952 & $4.944-355.998$ & 0.001 \\
\hline PRISM-III score & 1.162 & $1.057-1.278$ & 0.002 \\
\hline Underlying diseases & 3.775 & $0.916-15.56$ & 0.066 \\
\hline Sepsis & 1.589 & $0.398-6.35$ & 0.512 \\
\hline Mechanical ventilation & 7.891 & $0.832-74.822$ & 0.072 \\
\hline Vitamin D deficiency & 1.12 & $0.304-4.122$ & 0.865 \\
\hline
\end{tabular}

OR: Odds ratio; CI: Confidence interval; PRISM: Pediatric risk of mortality score production, and the expression of antimicrobial peptides..$^{[12-14]}$ The data from this study showed that patients with sepsis diagnosed at admission had a lower 25(OH)D level; although, the difference was not statistically significant. Madden et al. ${ }^{[2]}$ demonstrated that children admitted to the PICU with severe septic shock had lower serum 25(OH)D levels than other critically ill children in the PICU. Another study from Ireland showed that children admitted to the PICU with suspected sepsis had lower $25(\mathrm{OH}) \mathrm{D}$ than a control group and inadequate $25(\mathrm{OH}) \mathrm{D}$ status was associated with confirmed sepsis and poor outcomes ${ }^{[15]}$ Data from adults in a recent meta-analysis reported a significant increase in infection rate and sepsis. ${ }^{[1]}$

Underlying illnesses could lead to reduced Vitamin D status through abnormal diet, altered metabolism, or reduced environmental ultraviolet exposure. In contrast to expectations, underlying illnesses had no significant influence on Vitamin D status at PICU admission, as has been noted in previous studies of critical illness in pediatric patients..$^{[2,3]}$ In the current study, no associations were observed between Vitamin D status and PRISM III score. Similarly, some previous studies have not found any association between VDD and severity score ${ }^{[4,5,16]}$ However, McNally et al. ${ }^{[3]}$ reported that with every additional point increase in PRISM III score, the likelihood of VDD increased by $8 \%$. A somewhat similar observation was reported by Madden et al ${ }^{[2]}$ who reported an OR of 1.19 (95\% CI 1.10-1.28) for a 1-quartile rise in PRISM III score per $5 \mathrm{ng} / \mathrm{ml}$ decrease in 25(OH)D levels. This inconsistency of association could be explained by the heterogeneous patient population in different studies and variations in the tools used to assess severity.

Furthermore, no difference was determined between the low and normal $25(\mathrm{OH}) \mathrm{D}$ groups of the current study in respect of the need for ventilation and PICU LOS, which was in agreement with the data reported by Rippel et al..$^{[4]}$ and Rey et al. ${ }^{[5]}$ However, McNally et al..$^{[3]}$ and Sankar et al. ${ }^{[7]}$ found VDD to be associated with a longer LOS. Geographic and ethnic differences, different reasons for PICU admissions, and variations in patient responses to acute stress and critical illness could explain the differences between studies.

The association between Vitamin D status and myocardial dysfunction, heart failure, and sudden cardiac death is a novel finding. ${ }^{[17-19]}$ The current study results demonstrated that patients with VDD had significantly higher catecholamine requirements. Madden et $a l .{ }^{[2]}$ also observed that patients who received catecholamine had lower levels of $25(\mathrm{OH}) \mathrm{D}$ than those who did not median 19.8 versus $24.3 \mathrm{ng} / \mathrm{ml}, P<0.0001$ and an increased use of vasopressors was correlated with decreasing $25(\mathrm{OH}) \mathrm{D}$ levels $\left(r=2.19, P<0.0001\right.$. Similarly, McNally et al.${ }^{[3]}$ reported lower mean $(\mathrm{SD}) 25(\mathrm{OH}) \mathrm{D}$ levels in patients who required catecholamine infusion $\left(45^{[19]} \mathrm{nmol} / \mathrm{L}\right.$ vs. $38.5^{[16]} \mathrm{nmol} / \mathrm{L}$, $P=0.006$ ) Other studies have found no association between VDD and requirements for catecholamine. ${ }^{[4,5]}$

No significant association was determined in the current study between Vitamin D status and mortality. Vitamin D 
levels did not differ in survivors and nonsurvivors and in the logistic regression analysis, VDD was not associated with mortality. Adult studies have found a higher risk of mortality in patients with VDD. ${ }^{[20-22]}$ McNally et al. ${ }^{[3]}$ found that on multivariate regression, a $25(\mathrm{OH}) \mathrm{D}$ concentration $<50 \mathrm{nmol} / \mathrm{L}$ was independently associated with a PICU mortality rate of $1.5 \%(5 / 326)$ and all 5 deceased patients had VDD. Similarly, Ayulo et al. ${ }^{[16]}$ reported that 5 of 6 deaths were in patients with VDD. Other studies have found no association between VDD and mortality.

\section{Conclusions}

In conclusion, in a population of children from the north of Turkey, VDD incidence was seen to be high at PICU admission. To the best of our knowledge, this is the first study related to $25(\mathrm{OH}) \mathrm{D}$ levels in critically ill pediatric patients in Turkey. The patients determined with VDD were older and heavier and were more likely to receive a catecholamine. No significant correlation was found between other markers of illness severity, including mortality, and Vitamin D level. Further studies are required to establish a causal link between Vitamin D deficiency state and critical illness.

\section{Financial support and sponsorship}

Nil.

\section{Conflicts of interest}

There are no conflicts of interest.

\section{References}

1. de Haan K, Groeneveld AB, de Geus HR, Egal M, Struijs A. Vitamin D deficiency as a risk factor for infection, sepsis and mortality in the critically ill: Systematic review and meta-analysis. Crit Care 2014;18:660.

2. Madden K, Feldman HA, Smith EM, Gordon CM, Keisling SM, Sullivan RM, et al. Vitamin D deficiency in critically ill children. Pediatrics 2012;130:421-8.

3. McNally JD, Menon K, Chakraborty P, Fisher L, Williams KA, Al-Dirbashi OY, et al. The association of Vitamin D status with pediatric critical illness. Pediatrics 2012;130:429-36.

4. Rippel C, South M, Butt WW, Shekerdemian LS. Vitamin D status in critically ill children. Intensive Care Med 2012;38:2055-62.

5. Rey C, Sánchez-Arango D, López-Herce J, Martínez-Camblor P, García-Hernández I, Prieto B, et al. Vitamin D deficiency at pediatric intensive care admission. J Pediatr (Rio J) 2014;90:135-42.

6. Prasad S, Raj D, Warsi S, Chowdhary S. Vitamin D deficiency and critical illness. Indian J Pediatr 2015;82:991-5.

7. Sankar J, Lotha W, Ismail J, Anubhuti C, Meena RS, Sankar MJ, et al. Vitamin D deficiency and length of pediatric Intensive Care Unit stay: A prospective observational study. Ann Intensive Care 2016;6:3.

8. Goldstein B, Giroir B, Randolph A, International Consensus Conference on Pediatric Sepsis. International pediatric sepsis consensus conference: Definitions for sepsis and organ dysfunction in pediatrics. Pediatr Crit Care Med 2005;6:2-8.

9. Andıran N, Çelik N, Akça H, Doğan G. Vitamin D deficiency in children and adolescents. J Clin Res Pediatr Endocrinol 2012;4:25-9.

10. Baeke F, Takiishi T, Korf H, Gysemans C, Mathieu C. Vitamin D: Modulator of the immune system. Curr Opin Pharmacol 2010;10:482-96.

11. Gordon CM, Feldman HA, Sinclair L, Williams AL, Kleinman PK, Perez-Rossello J, et al. Prevalence of Vitamin D deficiency among healthy infants and toddlers. Arch Pediatr Adolesc Med 2008;162:505-12.

12. Hewison M. Vitamin D and the immune system: New perspectives on an old theme. Endocrinol Metab Clin North Am 2010;39:365-79.

13. Hewison M. Vitamin D and the intracrinology of innate immunity. Mol Cell Endocrinol 2010;321:103-11.

14. Black PN, Scragg R. Relationship between serum 25-hydroxyvitamin $\mathrm{d}$ and pulmonary function in the third national health and nutrition examination survey. Chest 2005;128:3792-8.

15. Onwuneme C, Carroll A, Doherty D, Bruell H, Segurado R, Kilbane M, et al. Inadequate Vitamin D levels are associated with culture positive sepsis and poor outcomes in paediatric intensive care. Acta Paediatr 2015; 104:e433-8.

16. Ayulo $\mathrm{M}$ Jr., Katyal $\mathrm{CH}$, Agarwal $\mathrm{CH}$, Sweberg $\mathrm{T}$, Rastogi D, Markowitz M, et al. The prevalence of Vitamin D deficiency and its relationship with disease severity in an urban pediatric critical care unit. Endocr Regul 2014;48:69-76.

17. Zosky GR, Berry LJ, Elliot JG, James AL, Gorman S, Hart PH, et al. Vitamin D deficiency causes deficits in lung function and alters lung structure. Am J Respir Crit Care Med 2011;183:1336-43.

18. Dobnig H, Pilz S, Scharnagl H, Renner W, Seelhorst U, Wellnitz B, et al. Independent association of low serum 25-hydroxyvitamin $\mathrm{d}$ and 1,25-dihydroxyvitamin $\mathrm{d}$ levels with all-cause and cardiovascular mortality. Arch Intern Med 2008;168:1340-9.

19. Makariou S, Liberopoulos EN, Elisaf M, Challa A. Novel roles of Vitamin D in disease: What is new in 2011? Eur J Intern Med 2011;22:355-62.

20. Arnson Y, Gringauz I, Itzhaky D, Amital H. Vitamin D deficiency is associated with poor outcomes and increased mortality in severely ill patients. QJM 2012;105:633-9.

21. Braun A, Chang D, Mahadevappa K, Gibbons FK, Liu Y, Giovannucci E, et al. Association of low serum 25-hydroxyvitamin D levels and mortality in the critically ill. Crit Care Med 2011;39:671-7.

22. Braun AB, Gibbons FK, Litonjua AA, Giovannucci E, Christopher KB. Low serum 25-hydroxyvitamin $\mathrm{D}$ at critical care initiation is associated with increased mortality. Crit Care Med 2012;40:63-72. 